\title{
Defense against filoviruses used as biological weapons
}

\author{
Mike Bray* \\ Medical Officer, Biodefense Clinical Research Branch, OCR/OD/NIAID/NIH, 6700A Rockledge Drive, Room 5132, Bethesda, MD 20892, USA
}

Received 30 August 2002; received in revised form 13 September 2002; accepted 18 September 2002

\begin{abstract}
The filoviruses, Marburg and Ebola, are classified as Category A biowarfare agents by the Centers for Disease Control. Most known human infections with these viruses have been fatal, and no vaccines or effective therapies are currently available. Filoviruses are highly infectious by the airborne route in the laboratory, but investigations of African outbreaks have shown that person-to-person spread requires direct contact with virus-containing material. In consequence, filovirus epidemics can be halted by isolating patients and instituting standard infection control and barrier nursing procedures. The filovirus disease syndrome resembles that caused by other hemorrhagic fever viruses, necessitating studies in a biocontainment laboratory to confirm the diagnosis. Some progress has been made in developing vaccines and antiviral drugs, but efforts are hindered by the limited number of maximum containment laboratories. Terrorists might have great difficulty acquiring a filovirus for use as a weapon, but my attempt to do so because of the agents' ability to inspire fear. Accurate information is the best tool to prevent panic in the event of an attack.
\end{abstract}

Published by Elsevier Science B.V.

Keywords: Filovirus; Ebola virus; Marburg virus; Biological warfare; Bioterrorism; Biodefense

\section{Introduction}

The increased threat of terrorism necessitates an evaluation of the risk posed by various microorganisms as biological weapons. This is especially important in the case of the filoviruses, Marburg and Ebola, both because these agents pose a threat as lethal pathogens and because their use by terrorists might result in extreme fear and panic. Most of the public knowledge of these viruses is based on inaccurate and exaggerated accounts in popular books and movies. If terrorists were to cause even a few Ebola or Marburg infections in a number of cities, public perception of a threat of epidemic spread could cause major social and economic disruption. A limited attack might thus achieve an impact out of proportion to the actual number of illnesses and deaths.

Basic information on filovirus replication, pathogenesis and epidemiology can be found in standard texts (Sanchez et al., 2001; Bray, 2002) and will be only briefly summarized in this paper. Filoviruses are enveloped single-stranded negative-sense RNA viruses with an unusual filamentous morphology. Their replication cycle resembles that of the better known rhabdo- and paramyxoviruses. The genus

\footnotetext{
* Tel.: +1-301-451-5123; fax: +1-301-435-6739.

E-mail address: mbray@niaid.nih.gov (M. Bray).
}

Filovirus contains two species, Marburg and Ebola virus. Ebola has four recognized subtypes (Zaire, Sudan, Reston and Côte d'Ivoire), while Marburg has none.

Filoviruses are classified as "Category A" biological weapons by the US Centers for Disease Control and Prevention (CDC) because of their high virulence, demonstrated aerosol infectivity in the laboratory, and capacity for inducing fear and anxiety (Rotz et al., 2002). Ebola Zaire and Sudan and Marburg virus cause severe hemorrhagic fever in humans, with a high case fatality rate. Ebola Reston and Côte d'Ivoire may be somewhat less virulent, but little information is available (Bray, 2002). Work with all filovirus species requires Biosafety Level 4 (BSL-4) "space suit" containment.

Since the filoviruses were first discovered in 1967, only 10 outbreaks involving 30 or more victims and a handful of additional sporadic cases have been identified. The number of confirmed human infections still totals less than 2000. Except for the initial Marburg epidemic, which resulted from the unwitting importation of infected monkeys from Uganda into Europe, all human cases have occurred in central Africa. Because of that region's limited health care infrastructure, only a small amount of data has been obtained on the course of human filovirus infections. Most of what we know about filovirus pathogenesis comes from experiments in laboratory animals, principally non-human primates, which develop a rapidly lethal illness believed 
to closely resemble the human disease. The recent development of a mouse model of lethal Ebola virus infection has facilitated drug and vaccine testing (Bray et al., 1998). However, progress in development of effective vaccines and therapies has been hindered by the small number of laboratories with the required level of biological containment.

Despite the limited knowledge base, sufficient information is available to assess the threat of filoviruses as biological weapons and to make reasonable recommendations for defensive measures and plans for future research. As is true for all biowarfare agents, an effective defense against filoviruses require a comprehensive approach that includes the following elements:

- prevention of access to virus stocks;

- improved means of detection of deliberately induced disease outbreaks;

$\circ$ rapid medical recognition of the viral hemorrhagic fever syndrome;

- rapid laboratory identification of filoviruses in patient specimens;

$\circ$ prevention of person-to-person transmission;

- reliable decontamination procedures;

- development of effective vaccines;

$\circ$ development of effective antiviral therapy.

After a brief review of the nature of the filovirus biowarfare threat and the features of the disease in humans, each of these topics will be addressed in turn.

\section{Filoviruses as biowarfare agents}

Like all weapons, biowarfare agents take advantage of weakness. Although a variety of mechanisms are in place to protect the military and civilian populations of industrialized countries against infectious agents in food and water, it is impossible to provide them with a constant supply of purified air. The most dangerous form of biological warfare exploits this vulnerability by delivering pathogens directly to the lungs, which have a huge interior surface area that is highly susceptible to microbial infection. To reach this target, particles must be small enough to remain suspended in inspired air until they arrive in the terminal branches of the airways. Most particles larger than $15-20 \mu \mathrm{m}$ in diameter fall to the ground soon after leaving their source, while those in the range of 5-10 $\mu \mathrm{m}$ tend to become trapped in the upper airways (Ali et al., 1999). The most highly infectious particles are those in the $1-5 \mu \mathrm{m}$ range, which settle out in terminal bronchioles and alveolar sacs.

Filoviruses are highly infectious by the airborne route (Jaax et al., 1995; Johnson et al., 1995; Jahrling, 1997; Peters, 2001). The vulnerability of human populations to airborne agents makes it probable that terrorists who choose to use a filovirus as a weapon will attempt to deliver it by aerosol. Beyond that statement, there is no way to predict what form an attack might take. A major assault on an entire city seems inherently less likely than a small-scale effort, since the former would require a very large amount of highly infectious material, proper aerosolization equipment, and correct conditions of wind, temperature and humidity. Failing this, terrorists could choose the less ambitious option of releasing a smaller amount of aerosolized virus into an enclosed space. Their choice of target might be determined by a specific area of vulnerability, such as an accessible ventilation system. If an attack is suspected to be taking place or is actually detected while in progress, a variety of means of respiratory protection are available (see Section 8).

Alternatively, non-aerosolized material could be used to produce a limited number of infections. As discussed below, filoviruses are transmitted between humans in naturally occurring outbreaks through direct contact with virus-containing body fluids. Terrorists might therefore attempt to spread disease by contaminating surfaces, foods or beverages with a suspension of virus.

Because the American biological warfare effort was terminated only 2 years after the first Marburg outbreak and 7 years before Ebola virus was discovered, filoviruses were not formally tested by the US program for their potential as biowarfare agents (Christopher et al., 1997). In contrast, the Soviet Union reportedly took an aggressive interest in the filoviruses, in violation of the Biological Weapons Convention. Soviet laboratories acquired samples of Marburg virus soon after the initial 1967 outbreak. A former administrator of the Soviet program has provided a dramatic account of a secret effort to develop Marburg virus as an offensive weapon (Alibek and Handelman, 1999). There is still no independent confirmation of this information. However, research reports published by Russian investigators after the collapse of the Soviet Union reflect a strong interest in the aerosol infectivity and stability of freeze-dried Marburg virus - a preparation highly suitable for use as a biological weapon (Peters, 2000).

\section{Ebola and Marburg disease in humans}

The incubation period for Marburg or Ebola infection is usually 5-7 days, but may exceed 2 weeks. Illness is abrupt in onset, with fever and chills, headache, muscle pain, nausea, vomiting, abdominal pain and diarrhea. Some patients may have pharyngitis with a non-productive cough. About half develop a purplish-red maculopapular rash on the trunk and shoulders before the end of the first week of illness. All victims display some degree of impairment of blood coagulation. The signs usually consist of conjunctival hemorrhages, easy bruising, failure of venipuncture sites to clot, and the presence of blood in the urine or feces. Massive bleeding is much rarer than popular accounts suggest; it is generally limited to the gastrointestinal tract. The onset of shock is heralded by severe nausea and vomiting, prostration, tachypnea, anuria, and a fall in body temperature. Death usually occurs 6-9 days after the onset of illness. 
The high lethality of Marburg and Ebola viruses results from a combination of factors. After gaining access to the body, filoviruses infect macrophages and other cells of the mononuclear phagocytic system at the site of entry and in regional lymph nodes, then spread to fixed tissue macrophages in the liver, spleen and other tissues throughout the body (Zaki and Goldsmith, 1999; Stroher et al., 2001). Virions released from these cells infect nearby hepatocytes, adrenal cortical cells, fibroblasts and other cell types, including endothelial cells in the later stages of disease. Replication may be accompanied by suppression of Type I interferon responses that would normally restrict viral dissemination (Harcourt et al., 1999; Basler et al., 2000; Bray, 2001).

Infected macrophages become activated and release large quantities of cytokines and chemokines, which may increase the permeability of the endothelial lining of blood vessels and induce expression of endothelial cell-surface adhesion and procoagulant molecules (Villinger et al., 1999; Stroher et al., 2001; Hensley et al., 2002). Tissue destruction results in the exposure of underlying collagen and the release of tissue factor, contributing to the development of disseminated intravascular coagulation (DIC). The simultaneous occurrence of massive cytolysis, cytokine effects, fluid shifts, interstitial hemorrhage, and tissue ischemia resulting from diffuse obstruction of capillary blood flow by masses of virions and microthrombi produces the fatal outcome.

Infectious virus disappears from the blood of surviving Marburg and Ebola patients as the acute illness resolves, but some virus has been shown to persist in immunologically privileged sites, such as the anterior chamber of the eye and in seminal fluid. Both agents have been recovered from semen 2-3 months into the convalescent period (Martini, 1969; Rodriguez et al., 1999). Survivors of filovirus infection should be counseled and provided with condoms.

\section{Prevention of access to virus stocks}

If an aggressor state wished to use a filovirus to attack a city or a military force, its intelligence agents or sympathizers might be able to obtain the organism from a number of sources. Samples of Marburg and Ebola virus were distributed to many research laboratories after the first outbreaks in the 1960s and 1970s. They may still be preserved at sites other than the handful of officially recognized BSL-4 laboratories. It is feared that criminal organizations may have stolen samples of filoviruses and other potential biowarfare agents from laboratories in countries of the former Soviet Union and sold them to wealthy terrorist organizations, such as Al Qaeda. The activities of state-sponsored terrorist groups are also of major concern. A hostile state that possesses strict security control over its own population and territory might easily establish a clandestine laboratory in which to prepare a stock of highly infectious virus, which it could then hand off to a terrorist group.
An organization operating without state support would have a more difficult time acquiring a filovirus. One approach would be to attempt to obtain patient samples during an outbreak. Only a very dedicated and resourceful group would be able to carry off such a feat-but the Japanese cult group, Aum Shinrikyo, is said to have sent some of its members to Zaire in the early 1990s in an effort to obtain Ebola virus (Kaplan, 2000). There is no evidence that they succeeded. Personnel dealing with filovirus outbreaks should be aware of the potential attractiveness to terrorists of infectious material in their possession.

An independent terrorist group might also attempt to obtain a sample of virus from a BSL-4 laboratory, either by introducing a sympathizer into the staff or by identifying a disgruntled scientist willing to sell some virus. There is no report that this type of event has occurred, but attempts are nevertheless being made to improve security at such facilities. The effect of these measures is limited by the extreme difficulty of maintaining meaningful inventories of replicating agents in laboratories with active research programs and of detecting the loss of the tiny volume of seed material that would be needed to start a new virus culture.

\section{Early recognition of deliberately induced disease outbreaks}

If terrorists were to secretly release a filovirus in an urban area, a week or more would elapse before the first cases of illness appeared. For each infected individual, the incubation period would depend largely on the quantity of virus inhaled; those closest to the source of the aerosol would tend to become ill first.

It is very unlikely that the first patients to show up at medical facilities would be recognized as suffering from a filovirus infection. The diagnostic difficulty lies both in the non-specific nature of the early signs of illness and in the extreme improbability that a case of Marburg or Ebola infection would be seen anywhere outside of central Africa. Only when it had become apparent that some kind of attack had occurred would physicians begin to consider the possible role of various biological weapons.

As in all biowarfare scenarios, the detection of a deliberately induced outbreak will be based on the appearance of an unusually large number of similar cases of severe illness over a short period of time (CDC, 2001). Recognition may be significantly delayed if infected individuals disperse widely after exposure and become ill in different locations after variable incubation periods. Once the epidemiologic picture suggests the possibility of a biowarfare attack, the health care team must alert its local county or state health department, who will in turn notify national agencies. Medical personnel on site will then work together with state and federal investigators to identify the pathogen. All potentially infectious specimens must be appropriately labeled and stored, and all persons who may have come 
into contact with contaminated materials must be identified. Further guidance on outbreak management will be provided by the health surveillance system and by the CDC or other national health authority. Information can be obtained from the CDC web site, http://www.bt.cdc.gov.

\section{Rapid medical recognition of the viral hemorrhagic fever syndrome}

Ebola and Marburg viruses are members of a large and diverse collection of enveloped RNA viruses that cause hemorrhagic fever in humans. Other pathogens in this group, such as the yellow fever, Rift Valley fever, and CrimeanCongo hemorrhagic fever viruses, cause diseases resembling filovirus infections, but with a lower case fatality rate (Jahrling, 1997). Some non-viral diseases, such as malaria, typhoid fever and leptospirosis, may also have similar clinical features. There are therefore no unique clinical findings by which Ebola or Marburg infection can be recognized. Specific virologic tests are required for diagnosis, as described below.

Physicians will be most likely to suspect a filovirus infection if a previously healthy person becomes abruptly ill with a high fever, and shows the following signs and symptoms:

- hemorrhagic manifestations, perhaps limited to the eyes and mucous membranes;

- a maculopapular rash, typically on the trunk, without other skin lesions;

- steady worsening of illness to intractable shock, with death within 1 week;

- absence of productive cough;

$\circ$ absence of neurologic involvement, other than obtundation.

It is not known whether aerosolized Marburg or Ebola virus would cause the formation of pulmonary infiltrates visible by chest X-ray. If not, the absence of abnormalities would provide an additional means of differentiating filoviruses from other biowarfare agents.

Abnormalities in standard laboratory tests will include an early neutrophilia, lymphopenia, elevated serum levels of liver-associated enzymes (particularly aspartate aminotransferase), marked thrombocytopenia and prolongation of coagulation times, with circulating fibrin degradation products and other features of DIC. Again, these findings are not unique to filovirus infections. Other hemorrhagic fever viruses may produce similar changes and must be considered as possible causes of severe febrile illness in an outbreak situation (Franz et al., 1997; Jahrling, 1997; Peters, 2000; Borio et al., 2002). Among other biowarfare diseases caused by Category A agents, only plague produces a notable coagulopathy. However, the pneumonic form of plague is also associated with a productive cough and pulmonary infiltrates by chest X-ray. Anthrax and tularemia are less likely to be confused with a filovirus infection, as they are not as- sociated with externally visible signs of hemorrhage, and in most cases produce significant changes on chest X-ray.

\section{Rapid laboratory confirmation of filovirus infection}

Tests employed to detect virus in samples from acutely ill patients include the reverse transcription-polymerase chain reaction (RT-PCR), antigen-capture enzyme-linked immunosorbent assay (ELISA), electron microscopy and growth in tissue culture (Geisbert et al., 1991; Ksiazek et al., 1999; Sanchez et al., 1999, 2001; Bray, 2002). Real-time RT-PCR has recently been shown to be a sensitive and rapid diagnostic method, which is capable of screening for multiple pathogens simultaneously (Drosten et al., 2002). In the USA, such assays are currently only available at CDC or the US Army Medical Research Institute of Infectious Diseases (USAMRIID). If medical personnel suspect a diagnosis of viral hemorrhagic fever, they must report the case to their local public health system, which will arrange for confirmatory testing to be performed. No material should be shipped to either of the above laboratories without prior consultation.

Patients who have been ill for a number of days will develop virus-specific IgM antibodies, which can be detected by ELISA (Ksiazek et al., 1999). After recovery, a retrospective diagnosis of Ebola or Marburg infection can be made by testing acute and convalescent serum samples for virus-specific IgG. In the event of a large epidemic, diagnosis can also be performed by immunoperoxidase staining of formalin-fixed skin biopsies from sick or deceased individuals (Zaki et al., 1999). This method has the advantages of simplicity, specificity and safety, since fixed material does not have to be handled in a BSL-4 laboratory.

As soon as a single case of filovirus infection has been confirmed, it will become much easier to recognize additional victims, as new patients with appropriate signs and symptoms can be linked to the time and place of a common exposure. However, the heightened state of alert resulting from an attack will inevitably result in reports of suspicious illnesses that will prove not to be filovirus infections on specific testing. These "false alarms" may cause problems for outbreak management and law enforcement investigation.

\section{Prevention of person-to-person transmission}

Retrospective analysis of the 1995 Ebola Zaire epidemic showed that the only individuals who were at significant risk of infection were those who came into direct physical contact with the body fluids (blood, feces, urine, vomit and sweat) of patients (Sadek et al., 1999; Dowell et al., 1999; Roels et al., 1999). Family caregivers, nurses and those who prepared a body for burial were at highest risk. Patients in the late stage of illness and the bodies of those recently deceased posed the greatest threat of disease transmission, 
presumably because their body fluids contained the largest amounts of virus. There was no evidence that victims were infectious before they developed symptoms.

The fact that the original Marburg outbreak and all Ebola epidemics have either "burned out" fairly rapidly on their own or have been brought to an end simply by instituting case-finding, quarantine and barrier nursing measures strongly supports the hypothesis that filovirus transmission occurs only through physical contact with contaminated material. Ebola outbreaks in Africa would have been much larger and considerably more difficult to bring to an end if the causative agent were transmitted in droplets from the upper respiratory tract, as in the case of influenza or smallpox.

The most common mechanism of human-to-human transmission appears to be the transfer of virus-containing material from the contaminated hands of caregivers to their own eyes or mouths. This process has been simulated in laboratory experiments in which monkeys were lethally infected by instilling drops of virus-containing fluid into these sites (Jaax et al., 1996).

The greatest risk of transmission of a filovirus from sick to healthy people will occur during the opening phase of an outbreak, when patients are being cared for by family members and examined and treated by health care workers, but the nature of their illness is still not known. In African Ebola outbreaks, this situation has resulted in a large number of infections among doctors and nurses, mainly because of the inability to employ proper infection control measures, such as the use of gloves, gowns and masks. However, failure to recognize the presence of a filovirus does not necessarily lead to the occurrence of numerous secondary infections. In the 1967 Marburg outbreak, physicians and nurses were completely ignorant of the nature of the disease agent and of the need for caution in handling contaminated materials, but only six secondary and no tertiary cases occurred. More recently, an Ebola patient in a South African hospital transmitted the infection to a nurse, but even though the two victims spent more than 3 weeks in hospital before the nature of their disease was finally recognized, no other cases occurred (Gradon, 2000; Richards et al., 2000). As for other viruses that pose a threat to health care workers, the risk of transmission will be greatly reduced if all personnel routinely adhere to infection control guidelines in patient care and follow universal precautions in specimen handling.

Once a diagnosis of filovirus infection has been made, experience obtained by World Health Organization (WHO)/CDC teams in managing African Ebola outbreaks indicates that patients can be managed effectively in essentially any setting, without undue risk to the medical staff, by employing standard patient isolation and barrier nursing procedures (Peters et al., 1996). Advice on protective clothing, methods of patient care, disinfection procedures and disposal of contaminated material is provided in several CDC/WHO publications (CDC, 1995, 1998), which can be downloaded from the CDC web site. All workers handling infectious material must wear protective clothing and use respiratory protection, which may be either a properly fitted N-95 mask or a powered air-purifying respirator (Hawley and Eitzen, 2000; McCullough, 2000). If conditions permit, laboratory personnel should handle all specimens in a laminar flow biosafety cabinet. Samples requiring processing at CDC or USAMRIID should not be packaged or shipped before consulting directly with those who will receive the material.

\section{Decontamination}

If an aerosol attack with a filovirus goes undetected, at least a week will elapse before the onset of the first illnesses. By that time, no infectious virus will remain in the environment, and there will be no need for surface decontamination. Even if an attack is detected while still in progress, or is discovered soon after completion through law enforcement investigation, persons who have not actually inhaled the agent will be at negligible risk of infection from any residual aerosolized virus that might linger in the environment, since the few viral particles that might adhere to skin, clothing or surfaces would degrade within hours through the action of UV light. However, as in all biowarfare situations, it would be prudent for people who may have been exposed to an aerosolized agent to take a full body shower with soap and to wash their clothing in hot water with detergent.

Decontamination becomes a very important concern when virus-containing liquids or other materials are present, either as body fluids from sick patients or as residues from liquid suspensions employed to carry out a terrorist attack. Filoviruses may survive at room temperature in liquid or dried material for a number of days. Belanov et al. (1996) found that Marburg virus remained infectious in dried blood for 4-5 days, depending on the initial virus concentration. Steam sterilization is the most effective method of inactivating filoviruses and other infectious agents. For the disinfection of surfaces and objects that are contaminated with blood or other body fluids, but cannot be sterilized by steam, the CDC recommends treatment with either a 1:100 dilution of household bleach (one-fourth of a cup in 1 gallon of water) or with any of the standard hospital disinfectants registered with the US Environmental Protection Agency, such as those based on quaternary ammonium compounds or phenol (CDC, 1995, 1998; http://www.epa.gov/oppad0001).

\section{Development of filovirus vaccines}

No filovirus vaccines are available for human use, but several candidates have given promising results in laboratory animals. Results obtained to date prove that non human primates can be protected against both Marburg and Ebola virus, and indicate that human vaccines against these agents are within the realm of possibility. 
Three major approaches have been used (Wilson et al., 2001; Geisbert et al., 2002; Hevey et al., 2002). The first consists of "naked DNA" vaccines, in which cDNA copies of filovirus genes are inserted into plasmids under the control of a promoter recognized by mammalian transcription systems. The plasmids are either injected intramuscularly or are propelled into the skin by "gene gun." DNA vaccines protected mice and guinea pigs against Ebola virus challenge (Vanderzanden et al., 1998; Xu et al., 1998), but have so far been insufficient on their own to protect non-human primates against the same agent. However, a modified approach, using DNA priming and a boost with a recombinant adenovirus, succeeded in protecting rhesus macaques against Ebola Zaire virus (Sullivan et al., 2000).

Alphavirus replicon vaccines also employ cDNA copies of viral genes, which in this case are inserted in place of genes encoding structural proteins in a replication-defective, attenuated form of Venezuelan equine encephalitis virus (Pushko et al., 2001). Replicon vaccines have protected rodents, but not non-human primates, against Ebola virus challenge (Pushko et al., 2001; Geisbert et al., 2002). However, a replicon vaccine was the first to protect monkeys against Marburg virus challenge (Hevey et al., 1998, 2002).

Inactivated filovirus vaccines have provided a variable degree of protection in animal models, but have generally only been weakly immunogenic (Ignatyev et al., 1996; Geisbert et al., 2002). A novel vaccine consisting of liposome-encapsulated irradiated Ebola virus induced solid protection in mice and elicited neutralizing antibodies in monkeys, but failed to prevent death after virus challenge (Rao et al., 2002; Geisbert et al., 2002).

\section{Development of effective antiviral therapy}

No specific therapy is currently available for Marburg or Ebola infection. Treatment is therefore supportive in nature, and includes intravenous fluid replacement, administration of analgesics and standard nursing measures. CDC/WHO publications, which can be downloaded from the CDC web site, provide recommendations for the care of hemorrhagic fever patients (CDC, 1998).

Experience with the experimental therapy of filovirus infections has recently been reviewed (Bray and Paragas, zz2002). There are few published reports describing attempts at specific treatment of human filovirus infections. Human convalescent serum has been considered a potential form of therapy since the Marburg outbreak, but its efficacy has never been proven. One individual accidentally inoculated with Ebola virus in the laboratory survived infection after receiving both convalescent serum and IFN- $\alpha$, but it is not clear that either treatment played a part in the outcome (Emond et al., 1977). A Russian laboratory worker accidentally infected with Marburg virus survived after undergoing a variety of therapeutic measures, including hemadsorption and dialysis, but there is no evidence that he benefited from these procedures (Nikiforov et al., 1994).

An attempt was made toward the end of the 1995 Ebola Zaire outbreak to demonstrate the therapeutic efficacy of whole blood transfusions from convalescent survivors (Mupapa et al., 1999). The treatment initially appeared to be effective, since out of eight laboratory-confirmed patients who received blood, only one died. However, subsequent analysis revealed that all of the survivors had already lived for an unusually long time after disease onset (a mean of 11 days) when they were transfused, and would therefore probably have recovered without therapy.

A variety of approaches have been employed in the experimental therapy of filovirus infections of laboratory animals. Antiserum treatment has given variable results, depending on the source of antibodies and the animal model employed. The most extensive experience has been obtained using purified $\mathrm{IgG}$ from horses hyperimmunized with Ebola Zaire virus. Inoculation of IgG shortly after virus challenge protected baboons and guinea pigs against Ebola Zaire challenge, but large doses only delayed the death of mice and cynomolgus macaques (Jahrling et al., 1996, 1999; Kudoyarova-Zubavichene et al., 1999). Use of this material for post-exposure treatment of accidental Ebola infections in laboratory workers has been approved in Russia. It has been administered to several investigators, though without clear evidence that they had actually been infected. Polyvalent homologous immune serum has also been effective in mice, preventing the death of both immunocompetent and immunodeficient animals challenged with mouse-adapted Ebola Zaire (Gupta et al., 2001). Monoclonal antibodies against Ebola GP also prevented death in mice, even when inoculated 2 days after virus challenge (Wilson et al., 2000). Human monoclonal antibodies that react strongly with Ebola GP, sGP or NP polypeptides have been produced from phage-display libraries constructed using mRNA from survivors of the 1995 Ebola Zaire outbreak (Maruyama et al., 1999). One such antibody was protective in guinea pigs (Parren et al., 2002), but therapeutic efficacy in non-human primates has not yet been reported.

IFN- $\alpha$ suppresses filovirus replication in monkey kidney cell culture and is highly effective in Ebola-infected mice when given as a series of doses beginning on the day of exposure (M. Bray, unpublished data). However, rhesus macaques treated with high doses of recombinant human IFN- $\alpha 2 b$ beginning on the day of infection with Ebola Zaire virus experienced only a 1-day delay in onset of illness, viremia and death, suggesting that IFN therapy is less effective in primates (Jahrling et al., 1999).

No antiviral drugs currently in clinical use, including ribavirin, provide any protection against filoviruses. However, a group of adenosine analogs that block the activity of a cellular enzyme, $S$-adenosylhomocysteine (SAH) hydrolase, strongly inhibit filovirus replication at low concentrations in vitro (Huggins et al., 1999). In Ebola-infected mice, 
these compounds cause massive release of IFN- $\alpha$, apparently reversing virus-induced suppression of the Type I IFN response (Bray et al., 2000, 2002). In non-human primates, treatment delayed the onset of viremia and illness, but did not prevent death (M. Bray and J. Huggins, unpublished data).

\section{Conclusion}

Biological weapons are unique in their invisibility and their delayed effect-factors that permit those who use them to sow confusion among their victims, while escaping undetected. Even more than sickness and death, a biowarfare attack would aim to cause fear, panic and paralyzing uncertainty, disrupting social and economic activity, breaking down government authority and impairing military responses. As demonstrated by the anthrax letters, the occurrence of even a few infections can create an enormous psychological impact-everyone feels threatened, no one knows what will happen next.

The principal reason that a hostile state or terrorist organization would go to the trouble of obtaining Ebola or Marburg virus to use as a weapon, rather than a more easily accessible biological agent such as $B$. anthracis, would be because of these viruses' reputation for causing a horrifying illness. Images on the nightly news of doctors, nurses and law enforcement personnel in full protective gear could cause widespread public distraction and anxiety. Biowarfare attacks are now a possibility. The public should be made familiar with basic infectious disease epidemiology and control measures, to increase the chance of a calm and reasoned response if an outbreak should occur.

\section{References}

Ali, J., Dwyer, A., Eldridge, J., Lewis, F., Patrick, W., Sidell, F., 1999. Jane's Chemical-Biological Defense Guidebook. Jane's Information Group, Alexandria, VA.

Alibek, K., Handelman, S., 1999. Biohazard. Random House, New York, NY, USA.

Basler, C., Wang, X., Muhlberger, E., Volchkov, V., Paragas, J., Klenk, H., Garcia-Sastre, A., Palese, P., 2000. The Ebola virus VP35 protein functions as a Type I IFN antagonist. Proc. Natl. Acad. Sci. USA 97, 12289-12294.

Belanov, E.F., Muntyanov, E.P., Kryuk, V.D., Spokolov, A.V., Bormotov, N.I., P'yankov, O.V., Sergeev, A.N., 1996. Survival of Marburg virus on contaminated surfaces and in aerosol. Voprosy Virusologii 41, 3234.

Borio, L., Inglesby, T., Schmaljohn, A., Hughes, J., Jahrling, P., Ksiazek, T., et al., 2002. Hemorrhagic fever viruses as biological weapons: medical and public health management. J. Am. Med. Assoc. 287, 2391-2405.

Bray, M., 2001. The role of the type I interferon response in the resistance of mice to filovirus infection. J. Gen. Virol. 82, 1365-1373.

Bray, M., 2002. Filoviridae. In: Richman, D.R., Whitley, R.J., Hayden, F.G. (Eds.), Clinical Virology, 2nd ed. ASM Press, Washington, DC, pp. $875-890$.
Bray, M., Davis, K., Geisbert, T., Schmaljohn, C., Huggins, J., 1998. A mouse model for evaluation of prophylaxis and therapy of Ebola hemorrhagic fever. J. Infect. Dis. 178, 651-661.

Bray, M., Driscoll, J., Huggins, J., 2000. Treatment of lethal Ebola virus infection in mice with a single dose of an $S$-adenosyl-L-homocysteine hydrolase inhibitor. Antiviral Res. 45, 135-147.

Bray, M., Raymond, R., Geisbert, T., Baker, R., 2002. 3-Deazaneplanocin A induces massively increased interferon-alpha production in Ebola virus-infected mice. Antiviral Res. 55, 151-159.

Bray, M., Paragas, J., 2002. Experimental therapy of filovirus infections. Antiviral Res. 54, 1-17.

Centers for Disease Control and Prevention, 1995. Update: management of patients with suspected viral hemorrhagic fever - United States. MMWR 44, 475.

Centers for Disease Control and Prevention and World Health Organization, 1998. Infection control for viral hemorrhagic fevers in the African health care setting. Centers for Disease Control and Prevention, Atlanta, pp. 1-198.

Centers for Disease Control and Prevention, 2001. Recognition of illness associated with the intentional release of a biologic agent. MMWR 44, 475.

Christopher, G., Cieslak, T., Pavlin, J., Eitzen, E., 1997. Biological warfare: a historical perspective. J. Am. Med. Assoc. 278, 412-417.

Dowell, S., Mukunu, R., Ksiazek, T., Khan, A., Rollin, P., Peters, C., 1999. Transmission of Ebola hemorrhagic fever: a study of risk factors in family members, Kikwit, Democratic Republic of the Congo, 1995. J. Infect. Dis. 179 (Suppl 1), S87-S91.

Drosten, C., Gottig, S., Schilling, S., Asper, M., Panning, M., Schmitz, H., Gunther, S., 2002. Rapid detection and quantitation of RNA of Ebola and Marburg viruses, Lassa virus, Crimean-Congo hemorrhagic fever virus, Rift Valley fever virus, dengue virus and yellow fever virus by real-time reverse-transcription PCR. J. Clin. Microbiol. 40, 2323-2330.

Emond, R., Evans, B., Bowen, E., Lloyd, G., 1977. A case of Ebola virus infection. Brit. Med. J. 2, 541-544.

Franz, D.R., Jahrling, P.B., Friedlander, A.M., McClain, D.J., Hoover, D.L., Byrne, W.R., Pavlin, J.A., Christopher, G.W., Eitzen, E.M., 1997. Clinical recognition and management of patients exposed to biological warfare agents. J. Am. Med. Assoc. 278, 399-411.

Geisbert, T., Rhoderick, J., Jahrling, P., 1991. Rapid identification of Ebola virus and related filoviruses in fluid specimens using indirect immunoelectron microscopy. J. Clin. Pathol. 44, 521-522.

Geisbert, T., Pushko, P., Anderson, K., Smith, J., Davis, K., Jahrling, P., 2002. Evaluation in nonhuman primates of vaccines against Ebola virus. Emerging Infect. Dis. 8, 503-507.

Gradon, J., 2000. An outbreak of Ebola virus: lessons for everyday activities in the intensive care unit. Critical Care Med. 28, 284-285.

Gupta, M., Mahanty, S., Bray, M., Ahmed, R., Rollin, P., 2001. Passive transfer of antibodies protects immunocompetent and immunodeficient mice against lethal Ebola virus infection without complete inhibition of viral replication. J. Virol. 75, 4649-4654.

Harcourt, B.H., Sanchez, A., Offermann, M., 1999. Ebola virus selectively inhibits responses to interferons, but not to interleukin-1beta, in endothelial cells. J. Virol. 73, 3491-3496.

Hawley, R., Eitzen, E., 2000. Bioterrorism and biological safety. In: Fleming, D., Hunt, D. (Eds.), Biological Safety: Principles and Practices. ASM Press, Washington, DC, pp. 567-577.

Hensley, L., Young, H., Jahrling, P., Geisbert, T., 2002. Proinflammatory response during Ebola virus infection of primate models: possible involvement of the tumor necrosis factor receptor superfamily. Immunol. Lett. 80, 169-179.

Hevey, J., Negley, D., Pushko, P., Smith, J., Schmaljohn, A., 1998. Marburg virus vaccines based upon alphavirus replicons protect guinea pigs and nonhuman primates. Virology 251, 28-37.

Hevey, M., Negley, D., Vanderzanden, L., Tammariello, R., Geisbert, J., Schmaljohn, C., Smith, J., Jahrling, P., Schmaljohn, A., 2002. Marburg virus vaccines: comparing classical and new approaches. Vaccine 20, 586-593. 
Huggins, J., Zhang, Z., Bray, M., 1999. Antiviral drug therapy of filovirus infections: $S$-adenosylhomocysteine hydrolase inhibitors inhibit Ebola virus in vitro and in a lethal mouse model. J. Infect. Dis. 179, S240S247.

Ignatyev, G., Agafonov, A., Streltsova, M., Kashentseva, E., 1996. Inactivated Marburg virus elicits a nonprotective immune response in rhesus monkeys. J. Biotechnol. 44, 111-118.

Jaax, N., Geisbert, T., Jahrling, P., Geoisbert, J., Steele, K., McKee, K., Negley, D., Johnson, E., Peters, C.J., 1995. Transmission of Ebola virus (Zaire strain) to uninfected control monkeys in a biocontainment laboratory. Lancet 346, 1669-1671.

Jaax, N., Geisbert, T., Vogel, P., Jaax, G., Topper, M., Jahrling, P., 1996. Experimental infection of rhesus monkeys by oral and conjunctival route of exposure. Arch. Pathol. Lab. Med. 120, 140-155.

Jahrling, P. 1997. Hemorrhagic fever viruses. In: Sidell, F.R., Takafuji, E.T., Franz, D.R. (Eds.), Medical Aspects of Chemical and Biological Warfare. Office of the Surgeon General, Washington, DC, pp. 592-600.

Jahrling, P., Geisbert, J., Swearengen, J., Jaax, G., Lewis, T., Huggins, J., Schmidt, J., LeDuc, J., Peters, C., 1996. Passive immunization of Ebola virus-infected cynomolgus monkeys with immunoglobulin from hyperimmune horses. Arch. Virol. Suppl. 11, 135-140.

Jahrling, P., Geisbert, T., Geisbert, J., Swearengen, J., Bray, M., Jaax, N., Huggins, J., LeDuc, J., Peters, C., 1999. Evaluation of immune globulin and recombinant interferon- $\alpha 2 b$ for treatment of experimental Ebola virus infections. J. Infect. Dis. 179, S224-S234.

Johnson, E., Jaax, N., White, J., Jahrling, P., 1995. Lethal experimental infection of rhesus monkeys by aerosolized Ebola virus. Int. J. Exp. Pathol. 76, 227-236.

Kaplan, D., 2000. Aum Shinrikyo. In: Tucker, J. (Ed.), Toxic Terror: Assessing Terrorist Use of Chemical and Biological Weapons. MIT Press, Cambridge, MA, pp. 207-226.

Ksiazek, T., Rollin, P., Williams, A., Bressler, D., Martin, M., Swanepoel, R., Burt, F., Leman, P., Khan, A., Rowe, A., Mukunu, R., Sanchez, A., Peters, C., 1999. Clinical virology of Ebola hemorrhagic fever virus: virus, virus antigen and $\mathrm{IgG}$ and IgM antibody findings among EHF patients in Kikwit, Democratic Republic of the Congo, 1995. J. Infect. Dis. 179, S177-S187.

Kudoyarova-Zubavichene, N., Sergeyev, N., Chepurnov, A., Netesov, S., 1999. Preparation and use of hyperimmune serum for prophylaxis and therapy of Ebola virus infections. J. Infect. Dis. 179, S218-S223.

Martini, G., 1969. Marburg agent disease in man. Trans. R. Soc. Trop. Med. Hyg. 63, 295-302.

Maruyama, T., Rodriguez, L., Jahrling, P., Sanchez, A., Khan, A., Nichol, S., Peters, C., Parren, P., Burton, D., 1999. Ebola virus can be effectively neutralized by antibody produced in natural human infection. J. Virol. 73, 6024-6030.

McCullough, N. 2000. Personal respiratory protection. In: Fleming, D., Hunt, D. (Eds.), Biological Safety: Principles and Practices. ASM Press, Washington, D.C., pp. 339-353.

Mupapa, K., Massamba, M., Kibadi, K., Kuvula, K., Bwaka, A., Kipasa, M., Colebunders, R., Muyembe-Tamfum, J., 1999. Treatment of Ebola hemorrhagic fever with blood transfusions from convalescent patients. J. Infect. Dis. 179, S18-S23.

Nikiforov, V., Turovskii, I., Kalinin, P., Akinfeeva, L., Katkova, L., Barmin, V., Riabchikova, E., Popkova, N., Shestopalov, A., Nazarov, V., 1994. A case of a laboratory infection with Marburg fever. Zh. Mikrobiol. Epidemiol. Immunobiol. 3, 104-106.

Parren, P., Geisbert, T., Maruyama, T., Jahrling, P., Burton, D., 2002. Preand postexposure prophylaxis of Ebola virus infection in an animal model by passive transfer of a neutralizing human antibody. J. Virol. 76, 6408-6412.

Peters, C., 2000. Are hemorrhagic fever viruses practical agents for biological terrorism? Emerg. Infect. 4, 201-209.

Peters, C., Jahrling, P., Khan, A., 1996. Patients infected with high-hazard viruses:scientific basis for infection control. Arch. Virol. Suppl. 11, $141-168$.
Pushko, P., Bray, M., Ludwig, G., Parker, M., Schmaljohn, A., Sanchez, A., Jahrling, P., Smith, J., 2001. Recombinant RNA replicons derived from attenuated Venezuelan equine encephalitis virus protect guinea pigs and mice from Ebola hemorrhagic fever virus. Vaccine 19, 142 153.

Rao, M., Bray, M., Jahrling, P., Alving, C., Matyas, G., 2002. Induction of immune responses in mice and monkeys to Ebola virus after immunization with liposome-encapsulated irradiated Ebola virus: protection in mice requires CD4+ T cells. J. Virol. 76, 9176-9185.

Richards, G., Murphy, S., Jobson, R., 2000. Unexpected Ebola virus in a tertiary setting: clinical and epidemiologic aspects. Critical Care Med. 28, 240-244.

Rodriguez, L., De Roo, A., Guimard, Y., Trappier, S., Sanchez, A., Bressler, D., Williams, A., Rowe, A., Bertolli, J., Khan, A., Ksiazek, T., Peters, C., Nichol, S., 1999. Persistence and genetic stability of Ebola virus during the outbreak in the Democratic Republic of the Congo, 1995. J. Infect. Dis. 179, S170-S176.

Roels, T., Bloom, A., Buffington, J., Muhungu, G., MacKenzie, W., Khan, A., Ndami, R., Noah, D., Rolka, H., Peters, C., Ksiazek, T., 1999. Ebola hemorrhagic fever, Kikwit, Democratic Republic of the Congo, 1995: risk factors for patients without a reported exposure. J. Infect. Dis. 179, S92-S97.

Rotz, L., Khan, A., Lillibridge, S., Ostroff, S., Hughes, J., 2002. Public health assessment of potential biological terrorism agents. Emerging Infect. Dis. 8, 225-229.

Sadek, R., Khan, A., Stevens, G., Peters, C., Ksiazek, T., 1999. Ebola hemorrhagic fever, Democratic Republic of the Congo, 1995: determinants of survival. J. Infect. Dis. 179, S24-S27.

Sanchez, A., Ksiazek, T., Rollin, P., Miranda, M., Trappier, S., Khan, A., Peters, C., Nichol, S., 1999. Detection and molecular characterization of Ebola viruses causing disease in human and nonhuman primates. J. Infect. Dis. 179, S164-S169.

Sanchez, A., Peters, C., Rollin, P., Ksiazek, T., Murphy, F. 2001. Filoviridae: Marburg and Ebola viruses. In: Fields, B.N., Knipe, D.M., Howley, P.M. (Eds.), Fields Virology. Lippincott-Raven, pp. 11611176.

Stroher, U., West, E., Bugany, H., Klenk, H., Schnittler, H., Feldmann, H., 2001. Infection and activation of monocytes by Marburg and Ebola viruses. J. Virol. 75, 11025-11033.

Sullivan, N., Sanchez, A., Rollin, P., Yang, Z., Nabel, G., 2000. Development of a preventive vaccine for Ebola virus infection in primates. Nature 408, 605-609.

Vanderzanden, L., Bray, M., Fuller, D., Roberts, T., Custer, D., Spik, K., Jahrling, P., Huggins, J., Schmaljohn, A., Schmaljohn, C., 1998. DNA vaccines expressing either the GP or NP genes of Ebola virus protect mice from lethal challenge. Virology 246, 134-144.

Villinger, F., Rollin, P., Brar, S., Chikkala, N., Winter, J., Sundstrom, J., Zaki, S., Swanepoel, R., Ansari, A., Peters, C., 1999. Markedly elevated levels of interferon (IFN)-gamma, IFN-alpha, interleukin (IL)-2, IL-10, and tumor necrosis factor-alpha associated with fatal Ebola virus infection. J. Infect. Dis. 179, S188S191.

Xu, L., Sanchez, A., Yang, Z., Zaki, S., Nabel, E., Nichol, S., Nabel, G., 1998. Immunization for Ebola virus infection. Nat. Med. 4, 37-42.

Wilson, J., Bosio, C., Hart, M., 2001. Ebola virus: the search for vaccines and treatments. Cell Molec. Life Sci. 58, 1-16.

Wilson, J., Hevey, M., Bakken, R., Guest, S., Bray, M., Schmaljohn, A., Hart, M., 2000. Epitopes involved in antibody-mediated protection from Ebola virus. Science 287, 1664-1666.

Zaki, S., Goldsmith, C., 1999. Pathologic features of filovirus infection in humans. Curr. Topics Microbiol. Immunol. 235, 97-115.

Zaki, S., Shieh, W., Greer, P., Goldsmith, C., Ferebee, T., Katshitshi, J., Tshioko, F., Bwaka, M., Swanepoel, R., Calain, P., Khan, A., Lloyd, E., Rollin, P., Ksiazek, T., Peters, C., 1999. A novel immunohistochemical assay for the detection of Ebola virus in skin: implications for diagnosis, spread, and surveillance fever. J. Infect. Dis. 179, S36S47. 